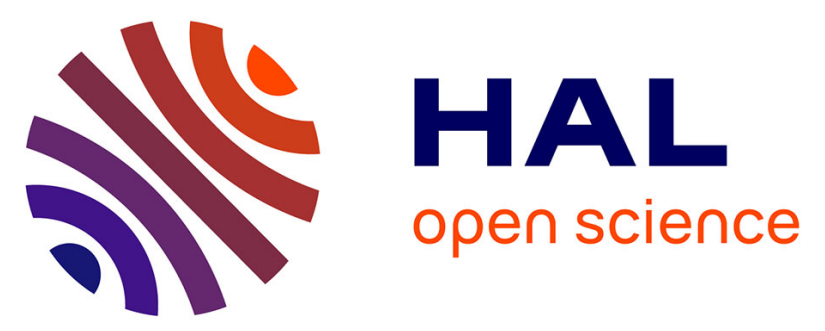

\title{
An easy-to-implement combinatorial approach involving an activity-based assay for the discovery of a peptidyl copper complex mimicking superoxide dismutase
}

Amandine Vincent, Jennifer Rodon Fores, Elodie Tauziet, Elodie Quévrain, Ágnes Dancs, Amandine Conte-Daban, Anne-Sophie Bernard, Philippe Pelupessy, Koudedja Coulibaly, Philippe Seksik, et al.

\section{To cite this version:}

Amandine Vincent, Jennifer Rodon Fores, Elodie Tauziet, Elodie Quévrain, Ágnes Dancs, et al.. An easy-to-implement combinatorial approach involving an activity-based assay for the discovery of a peptidyl copper complex mimicking superoxide dismutase. Chemical Communications, 2020, 56, pp.399-402. 10.1039/C9CC07920C . hal-02378888

\section{HAL Id: hal-02378888 \\ https://hal.science/hal-02378888}

Submitted on 25 Nov 2019

HAL is a multi-disciplinary open access archive for the deposit and dissemination of scientific research documents, whether they are published or not. The documents may come from teaching and research institutions in France or abroad, or from public or private research centers.
L'archive ouverte pluridisciplinaire HAL, est destinée au dépôt et à la diffusion de documents scientifiques de niveau recherche, publiés ou non, émanant des établissements d'enseignement et de recherche français ou étrangers, des laboratoires publics ou privés. 


\title{
An easy-to-implement combinatorial approach involving an activity-based assay for the discovery of a peptidyl copper complex mimicking superoxide dismutase
}

\author{
Amandine Vincent, ${ }^{a}$ Jennifer Rodon Fores, ${ }^{a}$ Elodie Tauziet, ${ }^{a}$ Elodie Quévrain, ${ }^{a}$ Ágnes Dancs, ${ }^{b}$ \\ Amandine Conte-Daban, ${ }^{\mathrm{c}}$ Anne-Sophie Bernard, ${ }^{\mathrm{a}}$ Philippe Pelupessy, ${ }^{\mathrm{a}} \mathrm{K}$ oudedja Coulibaly, ${ }^{\mathrm{a}}$, \\ Philippe Seksik, ${ }^{d}$ Christelle Hureau, ${ }^{c}$ Katalin Selmeczi, ${ }^{b}$ Clotilde Policar ${ }^{* a}$ and Nicolas Delsuc ${ }^{* a}$
}

A combinatorial approach using a One-Bead-One-Compound method and a screening based on an SOD-activity assay was set up for the discovery of an efficient peptidyl copper complex. The complex exhibited good stability constants, suitable redox potentials and excellent intrinsic activity. This complex was further assayed in cells for its antioxidant properties and showed beneficial effect when cells were submitted to oxidative stress.

Among catalytic drugs, ${ }^{1,2}$ superoxide dismutase mimics (SOD mimics), able to catalytically dismutate superoxide into $\mathrm{H}_{2} \mathrm{O}_{2}$ and $\mathrm{O}_{2}(1)$, are of particular interest since oxidative stress, which results from an imbalance between reactive oxygen species (ROS) concentration and antioxidant defences, is involved in many pathologies. ${ }^{3}$ SOD mimics have been developed for the last three decades ${ }^{3-5,6}$ for their biological and therapeutic applications. ${ }^{7}$ Most of them are complexes involving an organic ligand and metal ions such as iron, manganese or copper to perform the redox dismutation of the superoxide anion. One of the main parameters to be controlled for a good SOD-activity is the redox potential of metal ions couple involved. Its value should be between the redox potentials of $\mathrm{O}_{2}{ }^{\bullet-} / \mathrm{O}_{2}$ and $\mathrm{H}_{2} \mathrm{O}_{2} / \mathrm{O}_{2}{ }^{\bullet-}$, an optimal value being the mid-point of these two potentials at physiological $\mathrm{pH}^{6,8,9}$

$$
2 \mathrm{O}_{2}^{\cdot-}+2 \mathrm{H}^{+} \rightarrow \mathrm{H}_{2} \mathrm{O}_{2}+\mathrm{O}_{2}
$$

Peptide-based SOD mimics have also been extensively explored. ${ }^{10-16}$ Peptidyl ligands are valuable since their synthesis on solid support is easy and very versatile; they are biocompatible, easily metabolized and they can be conjugated to vector. However, the rational design of the peptide sequence to obtain a thermodynamically stable complex with the adequate redox potential still remains a challenge. To tackle these obstacles, a valuable alternative is the use of a combinatorial approach. ${ }^{17,18}$ Using a one-bead-one-compound

\footnotetext{
a. Laboratoire des biomolécules, LBM, Département de chimie, Ecole normale supérieure, PSL University, Sorbonne université, CNRS, 75005 Paris, France b. Laboratoire Lorrain de Chimie Moléculaire, L2CM UMR 7053 Université de Lorraine - CNRS, Faculté des Sciences et Technologies, Bvd des Aiguillettes, BP 70239,54506 Vandoeuvre-lès-Nancy cedex

c. CNRS, LCC (Laboratoire de Chimie de Coordination), 205 route de Narbonne, BP 44099, 31077 Toulouse Cedex 4, France

d. Centre de Recherche Saint Antoine, INSERM, UMRS 938, Metabolism Inflammation Department, 184 rue du Faubourg Saint-Antoine, 75012 Paris France

Electronic Supplementary Information (ESI) available: [Additional figures, schemes and tables and experimental procedures]. See DOI: 10.1039/x0xx00000x
}

(OBOC) method, a large panel of rather small peptides (less than 20 amino acids) can be easily produced, allowing the exploration of a vast and flexible structure and reactivity space. Examples of bioactive peptidyl complexes found by combinatorial chemistry are very scarce and, to the best of our knowledge, such approach has never been applied for the discovery of peptide-based redox active complexes including those mimicking SOD activity. ${ }^{19}$ In this context, we have designed a strategy associating the preparation of a combinatorial library of peptidyl metal complexes on solid support with a screening involving an activity-based assay with an easy-to-analyse read-out for the discovery of new efficient SOD mimics. The activity assay is inspired from the functional assay used to characterize SOD on electrophoretic gels. ${ }^{20}$ This leads to the selection of a hit complex that has been synthesized on a larger scale, characterized in details and studied on cellular models of oxidative stress which is unprecedented for peptidyl metal complexes.

To generate the library of peptidyl ligands, the design of the sequence has been inspired by the natural copper-zinc SOD which exhibits three to four imidazoles from histidines bound to the copper metal ion at its active site. ${ }^{21}$ The design of the sequence we have chosen to explore rely on a combination of the three most efficient $\mathrm{Cu}^{2+}$ binding motifs $\mathrm{HXHH}, \mathrm{HXHXH}$ and HXXHXXH leading to the sequence Ac- $\mathrm{X}_{1} \mathrm{H}_{2} \mathrm{H}_{3} \mathrm{X}_{4} \mathrm{H}_{5} \mathrm{H}_{6} \mathrm{X}_{7} \mathrm{H}_{8}$ with $\mathrm{X}$ not being a histidine. To increase the chemical space and favour the formation of a $\mathrm{Cu}$ complex with an adequate redox potential, we have applied a guided combinatorial approach with a screening based on the anti-superoxide activity. We have chosen to introduce variability on the second, third and sixth positions in this sequence introducing amino acids other than a histidine, either coordinating or noncoordinating. Hence, aspartate, glutamate or tyrosine were chosen as coordinating amino acids but also non-coordinating amino acids (glycine and arginine) to possibly provide flexibility and charge variation. Only histidines were chosen for the fifth and eighth positions to increase the occurrence of $\mathrm{N}_{\mathrm{im}}$ in the coordination sphere. Finally, lysine was added at the fourth position to increase water solubility, while proline and leucine were chosen at first and seventh positions respectively as noncoordinating amino acids acting as spacers. The $\mathrm{N}$-terminal amino functions were acetylated to avoid any binding of the metal ion from the free terminal amine. This design of this 216-members library led to the general sequence Ac- 
$\mathrm{PZ}_{1} \mathrm{Z}_{2} \mathrm{KHZ}_{3} \mathrm{LH}-\mathrm{OH}$ where $\mathrm{Z}_{\mathrm{n}}$ corresponds to the positions where diversity has been introduced.

a)
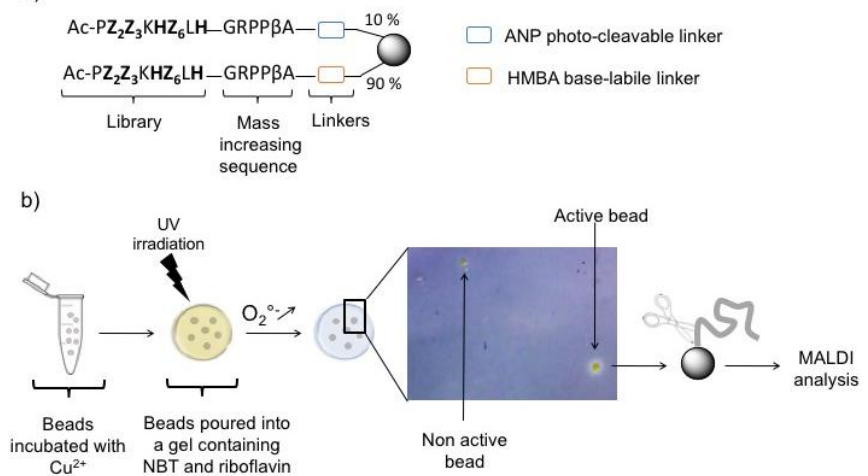

Figure 1. a) Schematic representation of the library on bead. b) Work flow of the Gel SOD assay screening: the resin $\left(50 \mathrm{mg}\right.$ ) is incubated in a $\mathrm{CuSO}_{4}$ solution (50 mM, $1 \mathrm{~mL}$ ). The gel was submitted to UV irradiation and active beads were collected. Peptide were cleaved from the resin in basic conditions and the sequences were determined by MALDI-TOF mass spectrometry. ANP stands for 3-amino-3-(2-nitrophenyl)propanoic acid and HMBA for 4-hydroxymethylbenzoic acid.

Inspired by B. Imperiali's work ${ }^{22}$ related to the discovery of lanthanide binding tag, a split and mix approach on solid support associated with a assay on gel has been employed using a classical Fmoc strategy (SI, Scheme S1). Two kinds of linkers have been grafted before the synthesis of the peptides: (a) $10 \%$ of a photocleavable linker (ANP) to release the peptides upon UV irradiation, enabling a clearer identification of active complexes, and (b) $90 \%$ of 4-hydroxymethylbenzoic acid (HMBA), which is only released in basic conditions (Figure 1a). ${ }^{22}$ A mass increasing sequence (GRPP $\beta A$ ), which adopts a random conformation has also been introduced to the construct to facilitate the further MALDI-TOF mass spectrometry analysis. ${ }^{23}$ As in all combinatorial libraries of peptides, isobaric sequences of peptides have been generated. In order to identify unambiguously the peptides by a simple mass spectrometry analysis, the strategy developed by Griesinger and coworkers and modified by Imperiali's group has been applied (see SI for more details). ${ }^{22,23}$ After peptide side chains deprotection with trifluoroacetic acid, beads were incubated with $\mathrm{CuSO}_{4}$, washed and immobilized in an agarose gel. The bioactivity assay involved the production of superoxide ions through UV irradiation of riboflavin. ${ }^{20}$ Nitroblue tetrazolium (NBT), a yellow reactant, was added to the mixture as a colour-marker of the superoxide anion production since it reacts specifically with superoxide to give the purple formazan. In this assay, active complexes compete with NBT to react with the superoxide ion, precluding the formation of formazan. As a consequence, a yellow colour was an indication of an active complex bore by that bead, as opposite to a purple colour for an inactive complex (Figure 1b). During UV irradiation, a small fraction of the complexes bound to the bead with the photocleavable linker was released and diffused around the bead in the gel. This allowed to widen the area around the beads where no reaction with the NBT occurred, thus facilitating the naked-eye observation. Doing so, a high number of beads showed a positive result. To get more selectivity based on the thermodynamic stability of the complexes, we have thus increased the selective pressure on the complex stability by washing the beads with EDTA $(50 \mathrm{mM}$, $\mathrm{pH} 8)$, a very competitive ligand for $\mathrm{Cu}^{2+}(\log \beta($ EDTA-Cu $)=$ 18.8). ${ }^{24}$ This additional washing step allowed to remove the more loosely bound copper ions and/or to release the copper from complexes that are not kinetically inert within the washing period. To note, this step does not ensure that the remaining complexes are more stable or inert than EDTA-Cu complex since contributions from the confinement and accessibility due to the solid support may participate to the complexes stability and inertness. After washing, only $5 \%$ of the beads have shown a positive result. The beads that support active complexes were isolated from the gel, the peptide cleaved from the bead in basic conditions, and the sequences were analysed by MALDI-TOF mass spectrometry (Figure S1). About 1200 beads were assayed (each sequence being potentially tested 5 times) among which 20 complexes showed activity and, the sequence PDHKHHLH was found four times (Tables S1 and S2), consequently, the peptide: AcPDHKHHLH-NH $\mathrm{NH}_{2}$ (called OCP1) was selected for further investigations.

The OCP1- $\mathrm{Cu}^{2+}$ complex was fully characterized in solution using a panel of techniques. All the data are reported in the Table 1 and in the supporting information. A titration with $\mathrm{Cu}\left(\mathrm{ClO}_{4}\right)_{2}$ by potentiometry combined with UV-vis and circular dichroism spectroscopies showed that three $\mathrm{Cu}$ species predominate in solution for a 1:1 OCP1:Cu mixture at physiological $\mathrm{pH}$. Two species possess $3 \mathrm{~N}_{\mathrm{im}}$ and 1 deprotonated amide $\left(\mathrm{N}^{-}\right)$and differ only from the protonation state of a non-coordinating imidazole and the third species involves $2 \mathrm{~N}_{\mathrm{im}}$ and $2 \mathrm{~N}^{-}$in the $\mathrm{Cu}^{2+}$ coordination sphere ( $\mathrm{SI}$ Figures S2-7). The apparent dissociation constant $\left(\mathrm{K}_{\mathrm{D}}=1.2 \pm\right.$ $0.11^{-10}$ ) at $\mathrm{pH} 7.4$ (HEPES, $50 \mathrm{mM}$ ) was determined by a competition experiment. ${ }^{25}$ ( $\mathrm{SI}$, Figure S8). This value is in good agreement with the best apparent constant found for other peptidyl copper complexes mimicking SOD. To be an efficient catalyst for superoxide dismutation, the copper ion has to cycle between the two redox states $\mathrm{Cu}^{+}$and $\mathrm{Cu}^{2+}$. Consequently, to ensure a catalytic activity with several turnovers, the peptide- $\mathrm{Cu}^{+}$complex must be stable as well in physiological conditions. Thus, the coordination sphere with $\mathrm{Cu}^{+}$was also studied by ${ }^{1} \mathrm{H}$ NMR spectroscopy as previously performed in another context. ${ }^{26}$ Histidine protons are the most affected by the presence of $\mathrm{Cu}^{+}$(Figure S9) and no significant changes were observed for the aspartate proton signals or those from the backbone amides. The coordination of $\mathrm{Cu}^{+}$seems therefore to involve only $\mathrm{N}_{\mathrm{im}}$. A competition experiment was also performed to determine the apparent dissociation constant of OCP1 for $\mathrm{Cu}^{+}\left(\mathrm{K}_{\mathrm{D}}, \mathrm{Cu}^{+}=6.0 \pm 0.410^{-9}\right)$ (SI, Figure S10). ${ }^{27}$

Important features of SOD mimic catalysts rely on their redox behaviour. To be efficient, the system has to be reversible, fast and the redox potentials of the complex must be comprised between the redox potentials of the two couples $\mathrm{O}_{2}{ }^{\circ} / \mathrm{H}_{2} \mathrm{O}_{2}$ and $\mathrm{O}_{2} / \mathrm{O}_{2}{ }^{*-}(0.92 \mathrm{~V} / \mathrm{NHE}$ and $-0.18 \mathrm{~V} / \mathrm{NHE}$, respectively) with an optimal value at the mid-point 0.36 
V/NHE. ${ }^{6,8,9,28}$ The redox behaviour of OCP1-Cu was examined by cyclic voltammetry (Table 1, Figure S11) and was found poorly reversible as the difference between the anodic and cathodic redox potentials is approximatively $600 \mathrm{mV}$. This can be explained by a structure reorganization of the complexes when oscillating between the two redox states $\mathrm{Cu}^{+}$and $\mathrm{Cu}^{2+}, \mathrm{a}$ reminiscent behaviour of peptide or peptide-like $\mathrm{Cu}^{2+} / \mathrm{Cu}^{+}$ complexes. $^{29,30}$ The values of the redox potentials $\left(E_{\mathrm{pa}}=0.55\right.$ $\mathrm{V} / \mathrm{NHE}$ and $\mathrm{E}_{\mathrm{pc}}=-0.05 \mathrm{~V} / \mathrm{NHE}$ ) at physiological $\mathrm{pH}$ for the $1: 1$ copper/ligand complex are indeed suitable for the efficient dismutation of the superoxide ion.

Table 1. Thermodynamic and kinetics constants of representative $\mathrm{Cu}^{2+}$ complexes involving a peptidyl ligand.

\begin{tabular}{|c|c|c|c|c|c|}
\hline $\begin{array}{l}\text { Ligand } \mathrm{L} \\
\qquad \mathrm{L} / \mathrm{Cu} \text { ratio }\end{array}$ & $\begin{array}{l}\mathrm{IC}_{50} \\
(\mu \mathrm{M})\end{array}$ & $\begin{array}{l}k_{a p p M C F}{ }^{g} \\
\left(\mathrm{M}^{-1} \mathrm{~s}^{-1}\right)\end{array}$ & $\mathrm{E}(\mathrm{V}) / \mathrm{NHE}$ & $\begin{array}{c}\text { Coordination } \\
\text { sphere }\end{array}$ & Reference \\
\hline \multicolumn{6}{|l|}{ OCP1 } \\
\hline $1 / 1$ & $0.124^{\mathrm{a}}$ & $2.3 .10^{7}$ & $\begin{array}{l}E_{p a}=0.55 \\
E_{p c}=-0.05\end{array}$ & $\begin{array}{c}3 \mathrm{~N}_{\mathrm{im}}, 1 \mathrm{~N}^{-} \\
\text {and } 2 \mathrm{~N}_{\mathrm{im}}, 2 \mathrm{~N}^{-}\end{array}$ & this article \\
\hline $5 / 1$ & $0.060^{\mathrm{a}}$ & $4.8 .10^{7}$ & & & \\
\hline \multicolumn{6}{|l|}{ Ac-HVH-NH ${ }_{2}$} \\
\hline $1 / 1$ & $\begin{array}{l}0.160^{\mathrm{b}} \\
0.160^{\mathrm{a}}\end{array}$ & $1.5 .10^{7}$ & & $2 \mathrm{~N}_{\mathrm{im}}, 2 \mathrm{~N}^{-}$ & $\begin{array}{c}31 \\
\text { this article }\end{array}$ \\
\hline \multicolumn{6}{|l|}{$\overline{\mathrm{cHH}-\mathrm{OH}}$} \\
\hline $2 / 1$ & $0.500^{c}$ & $4.8 .10^{7}$ & & $4 N_{\text {im }}$ & 13,32 \\
\hline \multicolumn{6}{|l|}{ Ac-HHGH-OH } \\
\hline $\begin{array}{r}1 / 1 \\
10 / 1 \\
\end{array}$ & $\begin{array}{l}0.130^{\mathrm{d}} \\
0.150^{\mathrm{e}} \\
0.250^{\mathrm{e}}\end{array}$ & $\begin{array}{l}2.2 \cdot 10^{7} \\
2.0 .10^{7} \\
1.2 \cdot 10^{7} \\
\end{array}$ & & $\begin{array}{l}3 \mathrm{~N}_{\mathrm{im}}, \mathrm{OH}^{-} \text {or } \\
2 \mathrm{~N}_{\mathrm{im}}, \mathrm{N}^{-}, \mathrm{H}_{2} \mathrm{O}\end{array}$ & 10,14 \\
\hline $\begin{array}{c}\text { HADHDHKK-NH } \\
1 / 1 \\
\end{array}$ & $0.110^{c}$ & $2.7 .10^{7}$ & & $3 \mathrm{~N}_{\text {im }}, \mathrm{NH}_{2 \text { term }}$ & 33 \\
\hline $\begin{array}{c}\text { Ac-HAAHGH-NH } \\
1 / 1 \\
1\end{array}$ & $0.048^{\dagger}$ & $6.2 .10^{7}$ & $E_{1 / 2}=0.33$ & $2 \mathrm{~N}_{\mathrm{im}}, \mathrm{N}^{-}$ & 10 \\
\hline CuZnSOD & $0.0016^{\mathrm{a}}$ & $1.8 .10^{9}$ & $E_{1 / 2}=0.12-0.3$ & $4 \mathrm{~N}_{\mathrm{im}}$ & $\begin{array}{c}\text { this article, } \\
14,28,34\end{array}$ \\
\hline $\mathrm{CuSO}_{4}$ & $0.603^{a}$ & $4.8 .10^{6}$ & & & this article \\
\hline
\end{tabular}

${ }^{\mathrm{a}} \mathrm{XTT}(100 \mu \mathrm{M})$ in HEPES buffer $(50 \mathrm{mM}, \mathrm{pH} 7.5) .{ }^{\mathrm{b}} \mathrm{NBT}(50 \mu \mathrm{M})$ in Tris buffer $(20 \mathrm{mM}$, $\mathrm{pH}$ 7.4). ${ }^{\mathrm{C}}$ Cytochrome $\mathrm{C}(50 \mu \mathrm{M})$ in phosphate buffer $(50 \mathrm{mM}, \mathrm{pH} 7) .{ }^{d}$ NBT $(50 \mu \mathrm{M})$ in phosphate buffer $(50 \mathrm{mM}, \mathrm{pH} 6.8) .{ }^{\mathrm{e}} \mathrm{NBT}(50 \mu \mathrm{M})$ in phosphate buffer $(50 \mathrm{mM}, \mathrm{pH} 7.5)$. ${ }^{\mathrm{f}} \mathrm{NBT}(50 \mu \mathrm{M})$ in phosphate buffer $(50 \mathrm{mM}, \mathrm{pH} 7.4) .{ }^{\mathrm{h}}$ Catalytic constants calculated from the $\mathrm{IC}_{50}$ are apparent since they are calculated from a mixture of species (several copper complexes and potentially free copper).

Intrinsic SOD-activity that refers to the kinetics of the reaction with superoxide, ${ }^{6}$ was investigated through the McCord and Fridovich assay using xanthine/xanthine oxidase as source of superoxide and XTT as UV-vis marker of superoxide production. This assay lead to the determination of the $\mathrm{IC}_{50}$ and the corresponding apparent catalytic constant

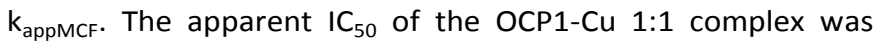
estimated at $124 \mathrm{nM}$, which corresponds to an apparent catalytic constant of $k_{\text {appMcF }}=2.4 .10^{7} \mathrm{M}^{-1} \mathrm{~s}^{-1}$ (See SI for more details). Under these conditions, 1 complex reacts with at least 6 superoxide molecules, showing that the complex is able to cycle for catalysis. Its activity represents $1.3 \%$ of the activity of CuZnSOD enzyme in the same conditions. ${ }^{6,9}$ These results at $\mathrm{pH} 7.5$ are consistent with the best catalytic constants found for peptide-based copper SOD mimics (Table 1). ${ }^{33}$ It has been controlled that hydrogen peroxide, produced continuously under Fridovich experiment, has no significant effect on the complex OCP1-Cu SOD activity $\left(\mathrm{IC}_{50}=110 \mathrm{nM}\right.$ in presence of catalase to be compared to $124 \mathrm{nM}$ without catalase, Figure S12). Upon increasing the ligand to metal ratio, the $I C_{50}$ decreases and reaches a plateau (at ca $60 \mathrm{nM}$ ) from a ratio
OCP:Cu 5:1, more likely because of the equilibrium shifting towards complex formation (Figure S13). To validate the screening strategy, a peptidyl (Ac-PHYKHRLH-NH $\mathrm{N}_{2}$ ) copper complex that belongs to the used library and exhibits a similar dissociation constant $\left(5.5 \pm 11^{-10}\right)$ and that has not been selected during the gel screening, has shown an $\mathrm{IC}_{50}$ three time higher that the OCP1-Cu (372 nM vs. $124 \mathrm{~nm}$ ) (Figure S14). This strongly supports the fact that only the most active complexes are selected.

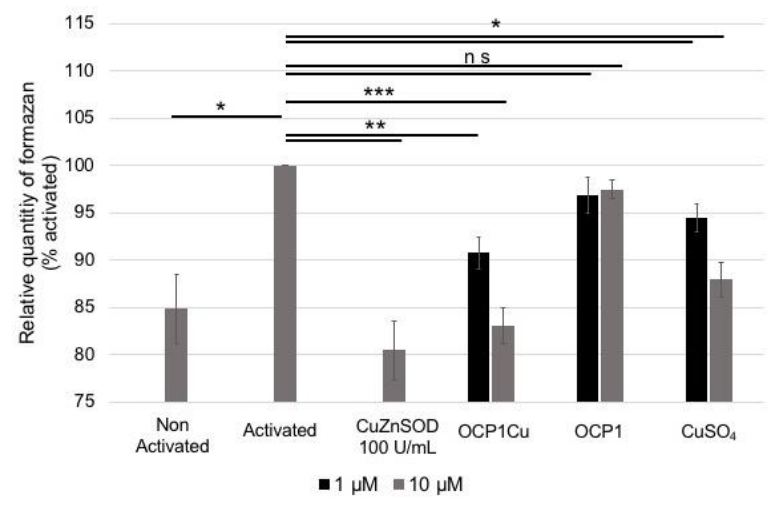

Figure 2. Superoxide dismutase activity on Raw 264.7 macrophages. The extracellular concentration of superoxide is measured by UV-vis spectroscopy using XTT as UV-vis marker $(470 \mathrm{~nm})$. The absorbance measured for activated cells was arbitrary set at $100 \%$. Data represent mean \pm SEM for five independent experiments. $\left({ }^{*}\right) \mathrm{p}<0.05,\left({ }^{* *}\right) \mathrm{p}<0.01,\left({ }^{* *}\right) \mathrm{p}<0.001$ vs. activated cells and $\mathrm{n} s$ means non-significant.

The 1:1 mixture was tested in more relevant biological conditions, namely on cellular models. Murine macrophages Raw 264.7, which is a cellular model of oxidative stress, has been selected for that purpose. ${ }^{35,36}$ On this cell line, the production and excretion of ROS in the extracellular medium, including superoxide, can be induced using lipopolysaccharide (LPS), interferon $\gamma$ (IFN- $\gamma$ ) and phorbol myristate acetate (PMA). The superoxide production was measured using the UV-vis marker XTT after incubation of the complexes at different non-toxic concentrations (toxicity data in Figure S15) for $1 \mathrm{hr}$. One hour was enough to induce the release of a significant amount of superoxide into the extracellular medium leading to very reproducible data (Figure S16). The results with the complex OCP1-Cu 1:1 clearly showed a dose-dependent effect (Figure 2). The peptidyl ligand showed no effect on superoxide production. Interestingly, incubation with the $\mathrm{Cu}^{2+}$ salt induced a decrease in formazan formation to a weaker extent than OCP1-CU at the same concentration. Since it has been suggested that the cellular reduction of the cellimpermeable XTT may also involve trans-plasma membrane electron transport ${ }^{37}$ and not only reduction by superoxide, the reduced formazan production observed upon incubation of $\mathrm{CuSO}_{4}$ may also be due to its interference with this pathway. Consequently, the same assay has been performed using ferricytochrome $c$ which is more selective for superoxide. ${ }^{35}$ OCP1-Cu 1:1 showed, as for XTT, a dose-dependent effect. Its activity at $5 \mu \mathrm{M}$ was similar to that of the natural SOD at $100 \mathrm{U}$ $\mathrm{mL}^{-1}$ (Figure S17-S18). In this case, neither the $\mathrm{Cu}^{2+}$ salt nor the peptidyl ligand showed an effect on the superoxide concentration, highlighting the need for the formation of the complex for a SOD activity in that context. 
The 1:1 complex was further investigated for its intracellular SOD-like activity on a cellular model (HT29-MD2) for which an inflammation mediated by oxidative stress can be induced. ${ }^{38}$ On this cell line, OCP1-Cu 1:1 complex and the ligand were found non-toxic up to $100 \mu \mathrm{M}$ whereas copper sulphate was not toxic at $10 \mu \mathrm{M}$ but toxic at $100 \mu \mathrm{M}$ (Figure S19). At $100 \mu \mathrm{M}$, the fact that the complex was not toxic, whereas $\mathrm{CuSO}_{4}$ was, constitutes an indirect proof that the complex was at least partially stable in this experiment. Cells were incubated with the compounds at non-toxic concentrations, activated with LPS and the inflammatory marker interleukine 8 (IL8) was measured. As expected, upon activation, an increase in IL8 production was measured and this production was decreased only after incubation of the complex at $100 \mu \mathrm{M}$. Neither the free ligand, nor the copper ion (at $10 \mu \mathrm{M}$ ) were found able to reduce this inflammation marker (Figure 3 ). These results suggest that the $\mathrm{Cu}$ complex is the active species. The recombinant CuZnSOD enzyme, which is catalytically very efficient but unable to penetrate cells, did not lead to a reduced IL8 concentration, suggesting that the antioxidant molecule needs to be internalized to exert its activity. All together, these results show that the selected complex is able to penetrate cells where it exerts its antioxidant activity leading to an interesting anti-inflammatory activity. So far, it is the first time that a peptidyl complex mimicking SOD activity has been successfully described in a cellular assay.

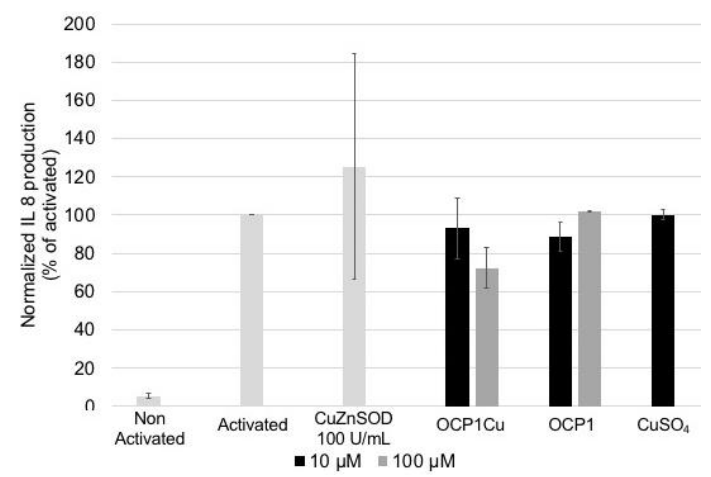

Figure 3. Quantification of the inflammatory marker IL8 by ELISA after incubation on epithelial cells HT29-MD2 $\left(3 \mathrm{~h}, 37^{\circ} \mathrm{C}\right.$ in HEPES $\left(0.1 \mathrm{M}\right.$, pH 7.5, glucose $\left.\left(1 \mathrm{~g} . \mathrm{L}^{1}\right)\right)$. Dose effect of OCP1-Cu complex. The absorbance measured for activated cells is arbitrary set at $100 \%$. Data represent mean \pm SEM for two independent experiments.

In conclusion, we have demonstrated that combining rationally design combinatorial library of peptidyl metal complexes and an activity- based assay enables the discovery of very efficient and stable catalysts for the desired biomimetic activity. The hit SOD mimic peptidyl complex was fully characterized and exhibited the expected properties. More interestingly, this complex showed anti-inflammatory properties in a cellular model with an oxidative stress mediated inflammation. These results open up new opportunities for the development of efficient and stable peptidyl metal complexes that can be used as catalytic drugs. In addition, this innovative combinatorial design associated with an activity based-assay is a strategy that can be used for many others activities as soon as an activity-based assay can be implemented.

\section{Acknowledgements}

We thank the IBPS SU, FR3631 mass spectrometry and peptide synthesis core facilities for access to the MALDI-TOF spectrometer and for providing us peptides respectively. ENS Paris-Saclay is also thanked for A.V. PhD fellowship. We gratefully thank A. Hoste for the simulations, S. Parant for technical help and C. Griesinger for the biblio software. This work was funded by ANR grants 16-CE07-0025-01 and 15CE07-0027.

\section{Notes and references}

1 J. Suh and W. S. Chei, Curr Opin Chem Biol, 2008, 12, 207-213.

2 J. J. Soldevila-Barreda and P. J. Sadler, Curr Opin Chem Biol, 2015, 25, 172-183.

3 I. Batinić-Haberle, J. S. Rebouças and I. Spasojević, Eds., Redox-Active Therapeutics, Springer International Publishing, Cham, 2016.

4 I. Batinic-Haberle, A. Tovmasyan and I. Spasojevic, Biolnorganic Reaction Mechanisms, 2013, 9, 35-58.

5 S. Signorella, C. Palopoli and G. Ledesma, Coord. Chem. Rev., 2018, 365, 75-102.

6 C. Policar, in Redox-active therapeutics, Springer Science, New York, NY, 2016, pp. 125-164.

7 C. Muscoli, S. Cuzzocrea, D. P. Riley, J. L. Zweier, C. Thiemermann, Z.-Q. Wang and D. Salvemini, Br. J. Pharmacol., 2003, 140, 445-460.

8 W. C. Barrette, D. T. Sawyer, J. A. Fee and K. Asada, Biochemistry, 1983, 22, 624 .

9 S. Durot, C. Policar, F. Cisnetti, F. Lambert, J.-P. Renault, G. Pelosi, G. Blain, H. Korri-Youssoufi and J.-P. Mahy, Eur. J. Inorg. Chem., 2005, 2005, 3513-3523.

10 G. Csire, S. Timári, J. Asztalos, J. M. Király, M. Kiss and K. Várnagy, J. Inorg. Biochem., 2017, 177, 198-210.

11 B. Bóka, A. Myari, I. Sóvágó and N. Hadjiliadis, J. Inorg. Biochem., 2004, 98, 113.

12 S. Timári, R. Cerea and K. Várnagy, J. Inorg. Biochem., 2011, 105, 10091017.

13 L. L. Costanzo, G. De Guidi, S. Giuffrida, E. Rizzarelli and G. Vecchio, J. Inorg. Biochem., 1993, 50, 273-281.

14 A. Jancsó, Z. Paksi, N. Jakab, B. Gyurcsik, A. Rockenbauer and T. Gajda, Dalton Trans, 2005, 3187.

15 A. Fragoso, P. Lamosa, R. Delgado and O. Iranzo, Chem. Eur. J., 2013, 19, 2076-2088.

16 U. P. Singh, R. K. Singh, Y. Isogai and Y. Shiro, Int. J. Pept. Res. and Ther., 2006, 12, 379-385.

17 K. S. Lam, M. Lebl and V. Krchňák, Chem. Rev., 1997, 97, 411-448.

18 M. Lebl, V. Krchňák, N. F. Sepetov, B. Seligmann, P. Strop, S. Felder and K. S. Lam, Biopolymers, 1995, 37, 177-198.

19 B. Archibald, O. Brümmer, M. Devenney, S. Gorer, B. Jandeleit, T. Uno, W. H. Weinberg and T. Weskamp, in Handbook of Combinatorial Chemistry, eds. K. C. Nicolaou, R. Hanko and W. Hartwig, Wiley-VCH Verlag GmbH \& Co. KGaA, Weinheim, FRG, 2004, pp. 885-990.

20 C. J. Weydert and J. J. Cullen, Nat. Prot., 2010, 5, 51-66.

21 J. A. Tainer, D. C. Richardson, E. D. Getzoff and J. S. Richardson, Nature, 1983, 306, 284-287.

22 M. Nitz, K. J. Franz, R. L. Maglathlin and B. Imperiali, ChemBioChem, $2003,4,272$.

23 C. Hoffmann, D. Blechschmidt, R. Krüger, M. Karas and C. Griesinger, J. Comb. Chem., 2002, 4, 79-86.

24 H. Irving and R. J. P. Williams, J. Chem. Soc., 1953, 0, 3192-3210.

25 A. Conte-Daban, V. Borghesani, S. Sayen, E. Guillon, Y. Journaux, G. Gontard, L. Lisnard and C. Hureau, Anal. Chem., 2017, 89, 2155-2162.

26 C. Hureau, V. Balland, Y. Coppel, P. L. Solari, E. Fonda and P. Faller, J. Biol. Inorg. Chem., 2009, 14, 995-1000.

27 B. Alies, B. Badei, P. Faller and C. Hureau, Chem. Eur. J., 2012, 18, 11611167.

28 S. Miriyala, I. Spasojevic, A. Tovmasyan, D. Salvemini, Z. Vujaskovic, D. St. Clair and I. Batinic-Haberle, Biochim. Biophys. Acta Mol. Basis Dis., 2012, 1822, 794-814. 
29 V. Balland, C. Hureau and J.-M. Savéant, Proc. Natl. Acad. Sci., 2010,

107, 17113.

30 A. Conte-Daban, B. Boff, A. Candido Matias, C. N. M. Aparicio, C. Gateau, C. Lebrun, G. Cerchiaro, I. Kieffer, S. Sayen, E. Guillon, P. Delangle and C. Hureau, Chem. Eur. J., 2017, 23, 17078-17088.

31 B. Bóka, A. Myari, I. Sóvágó and N. Hadjiliadis, J. Inorg. Biochem., 2004

98, 113.

32 S. Kubota and J. T. Yang, Proc. Natl. Acad. Sci., 1984, 81, 3283-3286.

33 D. Árus, A. Jancsó, D. Szunyogh, F. Matyuska, N. V. Nagy, E. Hoffmann, T. Körtvélyesi and T. Gajda, J. Inorg. Biochem., 2012, 106, 10-18.

34 M. F. J. M. Verhagen, E. T. M. Meussen and W. R. Hagen, Biochim. Biophys. Acta Gene. Subj., 1995, 1244, 99-103.

35 M. R. Filipović, A. C. W. Koh, S. Arbault, V. Niketić, A. Debus, U. Schleicher, C. Bogdan, M. Guille, F. Lemaître, C. Amatore and I. Ivanović-Burmazović, Angew. Chem. Int. Ed., 49, 4228-4232.

36 A.-S. Bernard, C. Giroud, H. V. Ching, A. Meunier, V. Ambike, C. Amatore, M. G. Collignon, F. Lemaître and C. Policar, Dalton Trans., 2012, 41, 6399-6403.

37 M. V. Berridge, P. M. Herst and A. S. Tan, Biotech. Annu. Rev., 2005, 11 127-152.

38 E. Mathieu, A.-S. Bernard, N. Delsuc, E. Quévrain, G. Gazzah, B. Lai, F. Chain, P. Langella, M. Bachelet, J. Masliah, P. Seksik and C. Policar, Inorg. Chem., 2017, 56, 2545. 